\title{
Working with, and for, Older People through Philanthropy-Funded Non-Profit Organisations in Ireland
}

\author{
Andy Cochrane ${ }^{1}$ (D) Sinead McGilloway ${ }^{1}$. \\ Michael Donnelly ${ }^{2}$
}

Published online: 24 May 2017

(C) Springer Science+Business Media New York 2017

\begin{abstract}
This case-study examined the role that philanthropic funding has played in enhancing the capacity of national NGOs in Ireland to advocate for, and with, older people. There was a relative lack of strategic focus on older people before the philanthropic work began (in 2003) and advocacy was only small-scale and uncoordinated. Philanthropic funding has enabled NGOs in Ireland to implement a considerable range of activities over a 7-year period (2007-2013). Three central findings emerged from a cross-sectional survey and documentary analysis including: 1) the value of developing more collaborative ways of working; 2) the importance of research and evidence to support policy and planning; and 3) the development of structures that promote the active involvement of older people in their communities. These factors have proved essential in strengthening the work of the NGOs and have enabled them, with support from others, to secure political commitment for key policy initiatives, including the development, for the first time, of a National Positive Ageing Strategy.
\end{abstract}

Keywords Advocacy·Philanthropy . Older people $\cdot$ Policy

\section{Introduction}

The world's population is ageing at an unprecedented rate with profound implications for individuals, families and societies (The Lancet 2014). Health and social care systems are already struggling to cope with meeting the needs of increasing numbers

Andy Cochrane

andy.cochrane@nuim.ie

1 Department of Psychology, Maynooth University, National University of Ireland Maynooth, Co Kildare, Ireland

2 Centre for Public Health, Queens University Belfast, Belfast, Northern Ireland 
of older people (e.g., Age UK 2014). Ireland still has a relatively young population when compared to other Western countries, but notwithstanding, the proportion of people aged $\geq 65$ is projected to increase from $11 \%$ in 2006 to $22 \%$ by 2041 (1.4 million; Centre for Ageing Research and Development Ireland: CARDI 2012). Until recently, any planning and provision for an ageing population was hampered by a dearth of information on the experience of ageing in Ireland (O'Shea and Conboy 2005), and ageing was not recognised as a core policy concern. There was considerable scope, therefore, for voluntary nonprofit organisations in Ireland to play a critical role in protecting the rights and interests of older people (Keenan 2008; Olshansky et al. 2011).

Traditionally in Ireland, public advocacy for older people was undertaken by a very small number of organisations and agencies. For example, a review of health care for older people in 2003, indicated that just five national organisations were involved, with only modest political effects (O'Neill and O'Keefe 2003). For some time, therefore, there was an urgent need to strengthen organisations which supported older people in order to build a 'cohesive participative capacity' (Equality Authority 2002, p.28). Similarly, a report by the National Economic and Social Forum (2005) highlighted a marked lack of advocacy for vulnerable older people, coupled with a notable absence of co-ordination between the various voluntary groups, to the extent that the voluntary sector was described as as under-resourced, weak and fragmented (Acheson and Harvey 2008).

It was within this context that the Atlantic Philanthropies Ageing Programme in Ireland was established in 2003 in an attempt to positively influence and build the capacity of the age sector to effect meaningful change for older people. Specifically, the aims of this programme were to enhance the rights of all older people to health and economic security and to enable them to advocate for a better quality of life for themselves and their peers. The Atlantic Philanthropies (AP) is a limited life foundation (1982-2020) which has made grants totalling $\$ 7.2$ billion through a number of programmes related to Higher Education, Ageing, Children and Youth, Population Health and Reconciliation programmes in seven countries throughout the world including Bermuda, the USA, Northern Ireland, Republic of Ireland, South Africa, Vietnam and Australia. The organisation's philosophy and grantmaking seek to advance opportunity and effect lasting change in the lives of disadvantaged and vulnerable people. The organisations funded by AP and the amounts awarded can be found at www.atlanticphilanthropies.org.

This case-study was undertaken to examine and critique the activities of key organisations in the ageing sector that were supported by the strategic thinking and planning of AP during a 7-year period (2007-2013). For the purposes of this study, the participating voluntary sector organisations were seen as operating according to four key criteria including: non-profit distribution; constitutional independence from the state; formal organisation; and receipt of voluntary input (Kendall and Knapp 2000).

\section{Method}

\section{Participant Organisations}

The study involved primarily a retrospective cross-sectional survey of the 13 national voluntary organisations who worked with, and/or for older people, and had received 
funding (totalling almost $\$ 35 \mathrm{~m}$ ) from AP during the period 2007-2013; two grantees received funding of over $\$ 5 \mathrm{~m}$ whilst a further five secured grants of over $\$ 2 \mathrm{~m}$. Five of the NGOs received more recent and ongoing funding from AP to continue specific areas of their work (e,g., helpline for older adults, education courses to promote civic engagement). The survey was supplemented by a comprehensive review of key documents including organisational reports grant proposals and evaluation reports.

\section{Measures}

A detailed questionnaire, based on the Payback Framework (Buxton and Hanney 1996), was devised specifically for purposes of gathering information from NGOs that had received funding from AP. The Payback model was originally developed as a framework within which to analyse the different stages of a research project, but in the case of this study, it provided a useful means of informing the content of the questionnaire and the subsequent analysis of the grantees' activities. The payback concept combines two elements; firstly, it describes the stages of a research project/programme from a research idea to inception, through the research process and successful execution, into dissemination and on towards any impact on people and society. Secondly, payback encompasses multidimensional categories from production of knowledge and capacity building through to influencing policy, social benefits, and broader potential economic outcomes (Hanney et al. 2004).

Key representatives from the target organisations were invited to complete and return the questionnaires ( $n=10 / 13 ; 77 \%$ response rate) which were then analysed on a group-basis; all responses to open-ended questions were subjected to a thematictype analysis involving the identification of key categories/themes relevant to the study objectives.

\section{Findings}

The work of the grantees encompassed a considerable range of operational and servicebased activities, and this case study focuses on four key collective outputs or results which emerged from the payback categories (shown below in brackets, albeit with some overlap between categories) including: (a) promoting collaborative ways of working (targetting and building capacity); (b) influencing national and local policy (influencing policy); (c) using and acting on research (knowledge production); and (d) engaging and empowering older people (social, health and sector benefits).

\section{(a) Promoting collaborative ways of working}

AP's early grant making to age-related voluntary organisations (2004-2008) attempted to address the relatively under-developed sector by supporting NGOs to develop comprehensive strategic plans and improve operational structures. These enabled the organisations to, for example, engage external consultants to undertake organisational reviews and improve and develop local and regional networks. These activities increased the capacity of the organisations to respond more effectively to the needs of older people. Subsequent grant making has continued this 
process and a key investment designed to address the fragmentation of the sector was the creation of two complementary umbrella organisations: Older and Bolder and the Ageing Well Network.

Older and Bolder was established in 2006 to develop the advocacy and policy capacity of its members underpinned by a rights-based perspective. The recognition of the unique contribution of each affiliated organisation while campaigining on agreed policy positions was critical to their work and, importantly, reduced the risk of "many competing voices" on a disparate range of issues (Carney 2009, p. 13). The Ageing Well Network (AWN) was created by AP in 2007, and brought together decision makers and leaders from the corporate sector, state agencies, academia and the voluntary sector. In contrast to Older and Bolder, AWN did not have a campaigning role; rather, it operated as an independent 'think-tank' and facilitated high-level strategic discussions between public, private and voluntary organisations.

These two organisations were always designed to have a limited lifespan and, indeed, both closed in 2013; nevertheless, the organisations included in the current case-study were operational during their life-span, and benefitted therefore, from the strategic, and collaborative work of Older and Bolder and AWN. Thus, the creation of these two organisations was an important and necessary precursor to creating a more cohesive, collaborative ageing sector in Ireland. AP's role in supporting and promoting greater collaboration and cohesion within the NGO sector required considerable time, effort, commitment and investment during a 10-year period. Encouragingly, a more recent collaborative initiative called Active Ageing Partnership (AAP) brought together three former members of Older \& Bolder and AWN (Active Retirement Ireland, Age and Opportunity, and Third Age). This partnership has enabled the organisations to synchronise their combined efforts to continue to promote the civic engagement of older people whilst maintaining their unique roles and functions. This is particularly important in view of the emphasis placed by AP on capacity building and sustainability beyond their funding period.

\section{(b) Influencing national and local policy}

Such capacity building within the NGO sector is/has been a key goal of the work of AP and was designed to, amongst other things, effect change and influence policy in all dimensions of the age sector (Cochrane et al. 2013). This is well illustrated by the complementary work of AWN and Older and Bolder in ensuring cross-party agreement for the development of a National Positive Ageing Strategy (NPAS) prior to the 2007 general election. The successful campaigning by Older and Bolder and other Atlanticfunded groups was important in maintaining pressure on subsequent governments.

For example, AWN helped to set the policy agenda by documenting the ways in which structures and systems needed to change in preparation for an ageing population (AWN 2012). They also hosted a national conference in 2012 designed to directly influence the content of the NPAS. Grantees made presentations directly to members of the Irish parliament, and this proved to be an effective mechanism for identifying 'sympathetic' champions and securing political commitment for the NPAS. This work also helped grantees to increase the visibility of their organisations, and become recognised as the 'go-to' groups representing older people. The now published NPAS acknowledges the significant role that the 
community and voluntary sector has played in its development and subsequent implementation 'given its advocacy on behalf of older people...commitment to articulating shared/agreed policy positions on behalf of organisations on issues key to the wellbeing of older people' (Department of Health 2013, p. 11). Importantly the Active Ageing Partnership (AAP) is now working with government departments to develop a comprehensive implementation plan for the strategy.

Campaigning locally on issues such as transport and health care, has traditionally been an important element of the work of some grantees (Harvey 2011), and AP has supported the introduction of a major initiative that provides, amongst other things, a more systematic approach to influencing policy at a local level. The development of the Age Friendly Counties and Cities (AFCC) programme builds on the WHO's Global Age Friendly Cities initiative (WHO 2007) which provided a blueprint for the creation of inclusive, age-friendly cities and communities. In Ireland, the small county town of Dundalk, County Louth, was one of the original 'cities' in the Global Age Friendly Cities research project, and Louth subsequently became the first county in Ireland to receive an age-friendly designation in 2009. A fully engaged local leadership across cooperating agencies was clearly vital in achieving the necessary commitment to take this initiative forward.

Importantly, Ireland demonstrated its commitment to the age friendly process by hosting an EU Summit on Healthy and Active Ageing in 2013, which culminated in the signing of the Dublin Declaration of Age Friendly Cities and Communities by senior political representatives from across Europe. The co-ordinating role of the AFCC has now been delegated to Age Friendly Ireland, an intermediary organisation established in 2014 to support and provide technical guidance to the 31 counties and cities involved in the programme. Collaboration between Age Friendly and the AAP should provide a vital link between the NPAS and the principles of age friendliness to ensure that the needs of older people are represented in the planning and development of cities and communities. The three organisations involved in the AAP have well-established programmes in local communities and their collaboration with Age Friendly Ireland will enable these to be more effectively integrated across the structures of the age friendly initiative into the future.

Understandably, however, there have been some limits to the degree of influence NGOs have been able to exert politically, particularly during a period of economic uncertainty. The fiscal climate in Ireland during 2007-2013 placed severe constraints on the development of new initiatives, whilst reductions in central funding increased pressure on the budgets of some organisations, resulting in shortfalls for financing campaigns that were not directly funded through AP. While factors outside the control of the grantees can influence their work, the findings suggest that, with support from others, the grantees have been able to influence developments that have the potential to inform and influence policy at both national and local levels.

\section{(c) Using and acting on research evidence}

AP funding has had a considerable impact on gerontology research (see Cochrane et al. 2013). For example, AP responded to the lack of data on ageing in Ireland through its flagship project - the Irish Longitudinal Study on Ageing (TILDA) - which is jointly funded by the Department of Health and Irish Life (an assurance and pension 
company). Unlike many other developed countries, there had been no large-scale population-based studies in Ireland prior to this, on which to inform planning for demographic change (Kearney et al. 2011). TILDA has now recruited over 8000 participants aged 50 and over, and has, gathered information on all aspects of health, economic and social circumstances. This presents a unique opportunity, amongst other things, to help shape and measure the outcomes of policy initiatives and interventions in Ireland. The findings from TILDA are already strengthening the advocacy work of the NGOs, by, for example, highlighting the need to support older carers, the prevalence of chronic disease in the older population and the benefits of staying active for healthy ageing.

As in many other countries, there is often a delicate relationship between research evidence and the, ultimately, political considerations that shape policy (Nutbeam 2004). The effective transfer of knowledge is contingent on strong links and consultation with end-users of research including government, NGOs and charities (Hagan Hennessy and Walker 2011). AP sought to strengthen these links by bringing together a wide coalition of policymakers and stakeholders in 2010 to secure a commitment from the government to develop a National Dementia Strategy. The call for a strategy had lasted several years and AP commissioned and funded a major research project - entitled Creating Excellence in Dementia Care (Cahill et al. 2012) - that provided crucial evidence to support the development of the strategy. The research has also provided an invaluable framework for the lobbying work of voluntary groups.

Additionally, AP funding enabled the national Alzheimer NGO to mobilise grass root campaigns and to ensure that the voice of people living with dementia was evident in advocacy activities. The Irish National Dementia Strategy was published in 2014, and it seems likely that the intervention of AP, including the commissioning of this major research project (Cahill et al. 2012), made a significant contribution to progress this vital strategy. As with the NPAS, it will be crucial for NGOs and other stakeholders to continue to campaign and ensure the effective implementation of the strategy.

Critically, the NGO grantees recognised the importance of research evidence, such as that on dementia care, in helping them to focus and strengthen their work when advocating for change, and attempting to influence policy development. Indeed, some projects have enabled the grantees to support innovative research themselves, including for example, exploring the experience of LGBT older adults. Furthermore, working with AP-supported academic centres/institutions has helped to strengthen and disseminate the work of NGOs; for example, academic teams have conducted evaluations of the work of the NGOs and supported their educational activities. For instance, the AAP developed, in collaboration with the Irish Centre for Gerontology in NUI Galway, and Age Friendly Ireland, a training course (Touchstone) designed to enhance the civic engagement of older people by providing them with the skills needed to play a meaningful role in creating sustainable age-friendly communities. Initial programmes hosted in two universities, with 125 participants, have been conducted and early evaluations of the course are very positive; roll out continues, with modifications to meet local needs and priorities.

Informal partnerships with researchers and other academics have proved mutually beneficial, with the practical and grassroots knowledge of NGOs helping to inform professional training and influence the academic research agenda. The development of relationships with professionals working in specific areas (e.g., health professionals in stroke care) can help to ensure that research findings are appropriately incorporated into campaigns and advocacy initiatives. 
The Irish Heart Foundation (IHF) provides a particularly useful model of successful advocacy work in terms of illustrating the importance of employing a co-ordinated and organised strategy, underpinned by a strong evidence base. Timing is often an important factor in advocacy work, and a number of factors facilitated the IHF. These included a sympathetic Minister for Health, a number of stroke specialist physicians returning to work in Ireland, and comprehensive European data demonstrating the benefits of selected stroke interventions (e.g., thrombolysis) (Wardlaw et al. 2009). In addition, the evidence from a National Audit of Stroke Care (Horgan et al. 2008) and a cost-effectiveness study (Smith et al. 2010) enabled the charity to present a compelling case to key decision makers, including those in the Department of Health. This is an excellent example of how a high level of research-awareness amongst grantees can help to ensure that services and policies in the future are based on sound evidence (Futurage 2011).

\section{(d) Engaging and empowering older adults}

Traditionally, ageing policies and strategies have focused on care provision, but as older people have become healthier and more active, there has been a shift in focus towards positive ageing emphasising that older people continue to be productive members of their community (Walker and Maltby 2012). Therefore, listening to, and responding to older people is a vital step in identifying priorities and key areas of concern for this population. It is also of critical importance that older adults, members and volunteers feel valued, consulted and knowledgeable about underlying issues and policies, so that they are more likely to engage with campaigns (Rees 1999). Indeed, strengthening older people's capacity to engage in active citizenship was one of AP's key objectives for the period 2008 to 2011.

Listening more effectively to their members through, for example the creation of regional councils to bring together local groups, has added legitimacy to the voice of AP-funded NGOs. The improved flow of information is now informing advocacy tactics such as public statements, letters to ministers, pre-budget submissions and presentations to government on issues such as the increasing costs of health insurance, cuts to fuel allowance and household benefits schemes. Encouragingly, there is also some evidence of the participation of older people at the design and implementation stages of the grants, and more generally in the work of the organisations. For example, older people have been directly involved in many of the decision-making stages of some projects and such involvement has helped to develop their capacity to become more engaged and to assume leadership roles (Harvey 2011). The establishment of local forums as part of the age friendly initiative has also provided regular, structured access for NGOs and older people to statutory service providers and their officials, thereby enhancing their opportunities to advocate for, and influence the development of, improved services (Walsh and Harvey 2012). Together, these structures have helped to engage a relatively diverse group of older people and ensure that a range of views, concerns and priorities can guide and inform the advocacy work of NGOs and planning in local communities.

However, a lack of empowerment can be a major barrier for some older adults to engage fully in active citizenship and advocacy, particularly among socially excluded groups. Three NGOs have developed innovative programmes that are designed to 
develop older people's ability to advocate for themselves, engage, and debate on all aspects of their lives. Firstly, a series of advocacy workshops have been conducted for the members of active retirement groups. Secondly, as mentioned earlier, educational courses for older people who want to make a difference in their local communities have been introduced, which are designed to develop critical awareness and the skills needed to engage in direct forms of advocacy.

Facilitating the participation and involvement of older adults in a range of activities in their local community can not only support advocacy but also has additional benefits on health and well-being. For example, an evaluation of Active Retirement Ireland (Ní Léime et al. 2012) indicated that members of affiliated groups report higher levels of quality of life, and lower levels of loneliness than the general population of older people in Ireland (as assessed in TILDA, Barrett et al. 2011). These findings are supported by the extensive body of literature documenting the positive relationship between active citizenship and volunteering and health and well-being in later life (Morrow-Howell et al. 2003; Emlet and Moceri 2012).

\section{Discussion}

This case study explored the collective activities of AP-funded organisations within the NGO ageing sector in the Republic of Ireland during the period 2007-2013. This funding has led, amongst other things, to a greater recognition of: 1) the value of developing more collaborative ways of working; 2) the importance of research and evidence to support policy and planning; and 3) the methods and structures that promote the active involvement of older people in their communities. By working together, the AP-supported grantees included in this study have been able to foster political commitment on ageing-related issues and influence policy at both local and national levels. This is especially demonstrated by the publication of important policy documents including the NPAS and the National Dementia Strategy, and the ongoing roll-out of the Age Friendly programme to cities and counties in Ireland. These are clearly vital in terms of achieving sustainable change and it seems highly likely that the progress, to date, would not have been achieved without the support of AP.

Effective advocacy depends upon the degree of political significance associated with an issue (Blancato 2004). Effective collaborations can create a "new political space" that draws attention and resources to a specific issue or challenge (Balassiano and Chandler 2010). It is apparent that the grantees, with encouragement and support from AP, recognised the benefits of establishing and maintaining collaborative ways of working when campaigning for policies and services (Carney et al. 2011). Individual effort, no matter how well organised, is likely to be "less effective than a well-managed coalition pushing a single message" (Knox 2010, p 75). Indeed the final grants from AP to support the AAP, will enable the organisations to mobilise and synchronise their combined efforts to continue to promote the civic engagement of older people, and embed their work more fully within the Age Friendly framework.

This coalition appears to be a very positive outcome of AP's concerted efforts over a number of years to promote collaborative working amongst the NGO sector in Ireland. Following the closure of Older and Bolder and AWN, it had been important for the remaining organisations to identify common causes if they were to be successful 
advocates for sustainable change. Crucially, the AAP collaboration successfully sidestepped previous historical difficulties whereby different organisations tended to present very diverse views to policy makers. For example, AAP and, importantly, three other NGOs agreed on, and presented, a cohesive message on ageing prior to the 2016 general election. Traditionally, the members of AAP did not take a lead in campaigning or lobbying, so bringing together and working with other NGOs with a strong history in this field - and delivering a joint message - was a significant achievement. Such coalitions and networks can be particularly useful in countries with a small, fragmented and under-resourced NGO sector; forging links within the sector and with those working in related fields, including academics, can support the development of collective strategies to inform tactical lobbying and campaigning (Yanacopulos 2005). The formation of coalitions can also be a reaction to external factors such as scarcity of resources and uncertainty surrounding funding (Yanacopulos 2005), which may inhibit creativity and innovation (Schmid et al. 2008). This is something of which the sector needs to be mindful, as AP has now formally exited the field in Ireland (albeit with a small number of active ongoing grants).

The ability to measure the impact(s) of their achievements is vital for NGOs in order to highlight the relevance of their work and ensure financial support into the future. However, a recent qualitative study emphasised the considerable challenges associated with measuring performance in the NGO sector (Carnochan et al. 2014) including, for example, defining outcomes to guide evaluation, and identifying the most appropriate methods to assess change. A new AP- supported programme, co-funded by the Department of Health, entitled the Healthy and Positive Ageing Outcomes Initiative, may help in this regard. National indicators of older people's health and well-being will be established, and regular 'State of the Nations Older Persons' reports will link changes in the lives of older people to policy development, including the implementation of the NPAS.

AP's continued, and indeed, increased funding on dementia research, education and awareness has the potential to make a considerable impact on the lives of people living with dementia, their family and carers. Perhaps there is still scope, however, for a more direct focus on awareness, prevention and health promotion to help reduce the burden of other chronic conditions including heart disease, arthritis, and diabetes (Christensen et al. 2009). Importantly, the Healthy and Positive Ageing Outcomes initiative includes a component on health promotion, whilst TILDA is also well placed to gather detailed information on the inter-related factors of ageing, co-morbidities and life-style behaviours (Leahy et al. 2014), and any impact and/or change(s) associated with health promotion interventions and policy initiative.

AP has done much to enhance research across the domains of gerontology to support planning for an ageing population. Nevertheless, it is important to acknowledge that older people's understanding of ageing and service needs can be far removed from that of researchers and scientists, making their involvement essential across all stages of the research process (Walker 2007). The NGO grantees have ensured that the views and experiences of older people are beginning to shape research priorities. Additionally, the AP-supported initiatives that promote and mobilise older adults as active members of organisations, volunteers, advocates and co-researchers should help to challenge the traditional view of older people as dependent and passive (Carney et al. 2011). 
It is also worth noting that, while philanthropic investment has become increasingly important and influential (Rogers 2011), there may be ethical issues in terms of how such funding aligns with the self-interest of the philanthropist (McGoey 2012) rather than the interests and needs of older people in the community. For instance, funders may hold implicit or explicit assumptions about how to influence policy while continuing to remain financially profitable (McGoey 2012), which may be at odds with the experiences and views of NGOs who work directly with older people. Indeed, philanthropic foundations may choose to set their own policy agenda without input from others, through their independent funding choices (Eikenberry 2006). In the context of AP, several mechanisms were in place to guard against this. Firstly, proposals for AP funding were traditionally by invitation only. Secondly, potential grantees were usually required to have demonstrated some evidence of their current and future capacity for success. Thirdly, AP's overall aim to transform the lives of disadvantaged and vulnerable groups reflects the objectives of a number of Irish NGOs concerned with ageing (for example, Older and Bolder campaigned to protect the economic security of older people, and Third Age, and others, work to minimise social exclusion). Lastly, intensive discussions and consultations with prospective grantees prior to the award of funding, helped to guide and inform project specification in line with AP's priorities as well as meeting the strategic goals of the NGOs involved.

A number of key lessons and implications for funders and organisations elsewhere have emerged from this case study with respect to advocacy (and the particular tactics and methods involved therein) and the future of the NGO sector. Specifically, it is useful for philanthropic organisations to retain the freedom and flexibility to identify and target issues that do not normally attract investment yet help to promote an age friendly agenda. Priorities may also shift over the course of a programme of investment as new findings/issues emerge, and these may help to inform subsequent rounds of funding. Real and meaningful change takes time, and measuring the impact of advocacy and other work of NGOs is challenging (Teles and Schmitt 2011). NGOs need to be able to demonstrate the success of their activities to ensure onoing funding, but they often pursue issues whose achievement is difficult to measure (Lee and Nowell 2015). Additionally, advocacy efforts are often cumulative and nonlinear making it difficult to attribute success to a particular tactic or organisation (Teles and Schmitt 2011). There is, therefore, a need to ensure that robust evaluation and knowledge translation plans are inherent components of research proposals, alongside the development of key indicators with which to measure outcomes.

Our study findings also speak to the importance of the political context within which ageing takes place. For example, the move towards active and productive ageing policies across much of Europe, not only reflects the improved health status of the older population, but also the economic imperative to encourage older people to stay in paid work in response to the unsustainability of many pension systems and age imbalances in the labour force (Walker and Maltby 2012). Indeed the qualifying age for the state pension in Ireland will rise from 65 to 68 years over the next decade, and other countries are planning similar increases. A country's welfare regime is, therefore, likely to influence, not only how people age, but also the nature of policy responses (Warburton and Grassman 2011). Additionally, the welfare context appears to influence the active participation of older adults. For instance, the number of older people who are members of voluntary organisations differs across welfare regime types; in Sweden 
only $5.5 \%$ of older population are not members of associations and nearly half of older people regularly volunteer, whereas in Germany, only $32.6 \%$ are members, and volunteering levels are comparatively low (Warburton and Grassman 2011). Volunteerism can address gaps in services and social care, particularly at times of austerity, yet productive ageing can work to promote social justice (Martinson and Minkler 2006). Part of AP's vision has been to foster the civic engagement of older adults as a mechanism for change; in response, NGOs have helped to build the capacity of older people to advocate for themselves and others, and raise concerns with politicians and other stakeholders. Indeed, civic engagement can provide important opportunities for older adults to make recognisable contributions to their community/ society, as long as it does not inadvertently become an 'expectation' that deepens the divide between the fit and productive versus those who are no longer able (or willing) (Minkler and Holstein 2008).

Overall, while this study focused on only a small number of organisations, the findings suggest investment in NGOs can help to build capacity both within the organisation and across the sector. Thus, philanthropic funding can be crucial in laying a firm and necessary foundation for a stronger, more cohesive and responsive age sector. The organisations that took part in this study, are now well placed to continue to advocate for, and contribute to, meeting the needs of an ageing population. This is particularly important given Ireland's relatively poor history in implementing policies and strategies. However, the impact of some policies and other initiatives are only likely to materialise in the mid- to longer-term and there remains a need for the NGOs to continue to work together to ensure that the potential for meaningful sustainable impacts are fully achieved. Nevertheless, the progress achieved thus far, demonstrates how philanthropic funding has played a major influential and strategic role in influencing and shaping the NGO ageing sector in Ireland.

\section{Compliance with Ethical Standards}

Conflict of Interest Prof. Sinead McGilloway received finding from Atlantic Philanthropies to conduct an independent evaluation of their Ageing programme. Dr. Andy Cochrane and Prof. Michael Donnelly declare no conflict of interest.

Informed Consent Informed consent was obtained from all individual participants included in this study.

Ethical Treatment of Experimental Subjects (Animal and Human) All procedures performed in studies involving human participants were in accordance with the ethical standards of the institutional and/or national research committee and with the 1964 Helsinki declaration and its later amendments or comparable ethical standards.

\section{References}

Acheson, N. \& Harvey, B. (2008). Social Policy, Ageing and Voluntary Action Dublin: Institute of Public Administration.

Age UK (2014). Care in Crisis 2014 http://www.ageuk.org.uk/latest-news/age-uk-publishes-damning-reporton-care-crisis/. 
Ageing Well Network. (2012). The new agenda on ageing. Dublin: AWN.

Balassiano, K., \& Chandler, S. M. (2010). The emerging role of nonprofit associations in advocacy and public policy: Trends, issues, and prospects. Nonprofit and Voluntary Sector Quarterly, 39(5), 946-955.

Barrett, A., Savva, G., Timonen, V. \& Kenny R.A. (2011). Fifty plus in Ireland 2011. First results from the Irish Longitudinal study on ageing (TILDA). Dublin: TILDA.

Blancato, R. B. (2004). Advocacy and aging policy: The prognosis. Generations, 28(1), 65-69.

Buxton, M., \& Hanney, S. (1996). How can payback from health services research be assessed? Journal of Health Service Research and Policy., 1, 35-43.

Cahill, S., O'Shea, E., \& Pierce, M. (2012). Creating excellence in dementia care. A research review for Ireland's National Dementia Strategy. Dublin: Trinity College Dublin.

CARDI. (2012). Ageing statistics for Ireland, north and south. Belfast: CARDI.

Carney, G. M. (2009). Citizenship and structured dependency: The implications of policy Design for Senior Political Power. Ageing and Society. doi:10.1017/So144686X0999011.

Carney, G., Dundon, T., Ní Léime, A., \& Loftus, C. (2011). Community engagement in Ireland's developmental welfare state: A study of the life cycle approach. Galway: Irish Centre for Social Gerontology.

Carnochan, S., Samples, M., Myers, M., \& Austin, M. J. (2014). Performance measurement challenges in nonprofit human service organisations. Nonprofit and Voluntary Sector Quarterly, 43(6), 1014-1032.

Christensen, C., Dobhlhammer, G., Rau, R., \& Vaupel, J. (2009). Ageing populations: The challenges ahead. Lancet, 374, 1196-1208.

Cochrane, A., McGilloway, S., Furlong, M., \& Donnelly, M. (2013). The role and contribution of philanthropy to the lives of older people in Ireland. International Journal of Aging and Society, 2(2), 13-23.

Department of Health. (2013). Positive ageing starts now! The National Positive Ageing Strategy. Dublin: Department of Health.

Eikenberry, A. M. (2006). Philanthropy and governance. Administrative Theory and Praxis, 28(4), 586-592.

Emlet, C. A., \& Moceri, J. T. (2012). The importance of social connectedness in building age-friendly communities. Journal Of Aging Research. doi:10.1155/2012/173247.

Futurage (2011). A Road Map for European Ageing Research. http://futurage.group.shef.ac.uk/ road-map.html.

Hagan Hennessy, C., \& Walker, A. (2011). Promoting multi-disciplinary and inter-disciplinary ageing research in the United Kingdom. Ageing and Society, 31(01), 52-69.

Hanney, S.R. Grant, J. Wooding, S. \& Buxton, M.J. (2004). Proposed methods fro reviewing the outcomes of health research: the impact of funding by the UK's 'Arthritis Research Campaign'. Health Research Policy Systems, 2(4). doi:10.1186/1478-4505-2-4.

Harvey, B. (2011). Report on age \& Opportunity get Vocal programme. Dublin: Brian Harvey Social Research.

Horgan, F., Hickey, A., McGee, H., \& O’Neill, D. (2008). National Audit of stroke care. Dublin: Irish Heart Foundation.

Kearney, P. M., Cronin, H., O’Regan, C., Kamiya, Y., Savva, G. M., Whelan, B., \& Kenny, R.-A. (2011). Cohort profile of the Irish Longitudinal study on ageing. International Journal of Epidemiology, 40(4), 877-884.

Keenan, O. (2008). Relationships and representation, challenges and opportunities for the voluntary and community sector in Ireland. Trinity College Dublin: Centre for Nonprofit Management.

Kendall, J., \& Knapp, M. (2000). Measuring the performance of voluntary organisations. Public Management., 2(1), 105-132.

Knox, C. (2010). Policy advocacy in Northern Ireland. Belfast: Atlantic Philanthropies.

Leahy, S., Nolan, A., O’Connell, J., \& Kenny, R. A. (2014). Obesity in an ageing society. In Implications for health, physical function and health service utilisation. Dublin: The Irish Longitudinal Study on Ageing.

Lee, C., \& Nowell, B. (2015). A framework for assessing the performance of nonprofit organisations. American Journal of Evaluation, 36(3), 299-319.

Martinson, M., \& Minkler, M. (2006). Civic engagement and older adults: A critical perspective. The Gerontologist, 46(3), 318-324.

McGoey, L. (2012). Philanthrocapitalism and its critics. Poetics, 40, 185-199.

Minkler, M., \& Holstein, M. B. (2008). From civil rights to... civic engagement? Concerns of two older critical gerontologists about a "new social movement" and what it portends. Journal of Aging Studies., 22, 196-204.

Morrow-Howell, N., Hinterlong, J., Rozario, P. A., \& Tang, F. (2003). Effects of volunteering on the wellbeing of older adults. Journal of Gerontology: Social Sciences, 58B(3), S137-S145.

NESF (National Economic and Social Forum). (2005). Care for Older People, Report No. 32. Dublin: NESF.

Ní Léime, Á., Callan, A., Finn, C., Healy, R. (2012). Evaluating the impact of membership of active retirement Ireland on the lives of older people, Dublin, Active Retirement Ireland.

Nutbeam, D. (2004). Getting evidence into policy and practice to address health inequalities. Health Promotion International, 19(2), 134-140. 
O'Neill, D., \& O'Keefe, S. (2003). "Health Care for Older People in Ireland". Journal of the American Geriatric Society, 51(9), 1280-1286.

O'Shea, E., \& Conboy, P. (2005). Planning for an ageing population: Strategic considerations. Dublin: National Council on Ageing and Older People.

Olshansky, S. J., Biggs, S., Achenbaum, A. W., Fried, F., Gutman, G., et al. (2011). The Global agenda council on the ageing society: Policy principles. Global Policy, 2(1). doi:10.1111/j.1758-5899.2010.00053.x.

Rees, S. (1999). Strategic choices for non-profit advocates. Non-profit and Voluntary Sector Quarterly., 28(1), $65-73$.

Rogers, R. (2011). Why philanthro-policymaking matters. Society, 48, 376-381.

Schmid, H., Bar, M., \& Nirel, R. (2008). Advocacy activities in nonprofit human service organizations: Implications for policy. Nonprofit and Voluntary Sector Quarterly, 37(4), 581-602.

Smith, S., Horgan, F., Sexton, E., \& Wiley, M. (2010). Cost of stroke in Ireland: Estimating the annual economic cost of stroke and transient ischaemia attack (TIA) in Ireland. Dublin: ESRI \& RCSI.

Teles S. \& Schmitt, M. (2011). The elusive craft of evaluating advocacy. Stanford Social Innovation Review, Summer: $39-43$.

The Equality Authority (2002). Implementing equality for older people. Dublin: The Equality Authority

The Lancet (2014). Global elderly care in crisis. Editorial, 383, March $15^{\text {th }}, 927$.

Walker, A. (2007). Why involve older people in research. Age and Ageing, 36, 481-483.

Walker, A., \& Maltby, T. (2012). Active ageing: A strategic policy solution to demographic ageing in the EU. International Journal of Social Welfare., 21(s1), S117-S130.

Walsh, K., \& Harvey, B. (2012). Review of age friendly counties Programme. Dublin: Ageing Well Network.

Warburton, J., \& Grassman, E. J. (2011). Variations in older people's social and productive ageing activities across different social welfare regimes. International Journal of Social Welfare, 20, 180-191.

Wardlaw, J., Murray, V., Berge, E. \& del Zoppo, G. (2009). Thrombolysis for acute ischaemic stroke. Cochrane Database of Systematic Reviews, 4 (CD000213).

World Health Organisation. (2007). Global age-friendly cities: A guide. France: WHO.

Yanacopulos, H. (2005). The strategies that bind: NGO coalitions and their influence. Global Networks, 5(1), 93-11.

Dr. Andy Cochrane : Dr. Cochrane is a research psychologist and has been involved in age -related research for the past eight years. Her research interests include activities that promote well-being and participation; the influence of implicit attitudes on behavior; evidence-based practice.

Prof Sinead McGilloway : Professor McGilloway is a senior academic and community/public health psychologist and has been involved in a wide range of research programmes based on mixed methodologies. She is the Director of the Mental Health and Social Research Unit and Principal Investigator of the ENRICH research programme.

Prof Michael Donnelly : Professor Donnelly is a social and behavioural scientist, with an extensive record in applied health and social care research. He has considerable experience in research relevant to policy and practice designed to develop effective services. 